\title{
Asset pricing, spatial linkages and contagion in real estate stocks
}

Article

Accepted Version

Milcheva, S. and Zhu, B. (2018) Asset pricing, spatial linkages and contagion in real estate stocks. Journal of Property Research, 35 (4). pp. 271-295. ISSN 1466-4453 doi: https://doi.org/10.1080/09599916.2018.1485725 Available at https://centaur.reading.ac.uk/77508/

It is advisable to refer to the publisher's version if you intend to cite from the work. See Guidance on citing.

To link to this article DOI: http://dx.doi.org/10.1080/09599916.2018.1485725

Publisher: Routledge

All outputs in CentAUR are protected by Intellectual Property Rights law, including copyright law. Copyright and IPR is retained by the creators or other copyright holders. Terms and conditions for use of this material are defined in the End User Agreement.

\section{www.reading.ac.uk/centaur}

\section{CentAUR}

Central Archive at the University of Reading

Reading's research outputs online 


\section{Taylor \& Francis Word Template for journal articles}

STANIMIRA MILCHEVA ${ }^{\mathrm{a}^{*}}$ AND BING ZHU

aUniversity College London, Bartlett CPM, 1-19 Torrington Place, London, UK, s.milcheva@ucl.ac.uk.

bepartment of Real Estate and Planning, University of Reading. UK. B.zhu@henley.reading.ac.uk. 


\title{
Asset Pricing, Spatial Linkages and Contagion in Real Estate Stocks
}

\author{
STANIMIRA MILCHEVA ${ }^{\mathrm{a}^{*}}$ AND BING ZHU ${ }^{\mathrm{b}}$
}

\begin{abstract}
Following recent methodological developments, we estimate a spatial multi-factor model (SMFM) which combines asset pricing techniques with spatial econometrics to assess systemic implications for REIT index returns. We distinguish between comovement due to market risk exposure (systematic risk) and comovement due to linkages between markets (spillover risk). We find that the spillover risk dramatically increases during the global financial crisis and can explain up to $60 \%$ of total asset variation. In the rest of the time, idiosyncratic risks have been the predominant type of risk in real estate stocks. Our results have implications for investors showing that the market can channel asset volatility leading to contagion during crisis periods and therefore residual linkages between country indices need to be accounted for as a means of assessing the diversification benefits of a global portfolio.
\end{abstract}

Keywords: Spatial MFM, spillover risk, idiosyncratic risk, contagion, listed property returns.

JEL Classifications: C23, G15, F36, R3 


\section{Introduction}

In the aftermath of the global financial crisis (GFC) investors have been trying to reassess the diversification benefits from investing internationally. Whereas international stock markets have been considered as highly volatile and interconnected, real estate is regarded as a more heterogeneous asset class with high idiosyncratic risk and low market risk exposure. Albeit originating in the US subprime mortgage market, the burst of the real estate bubble in the US had led to strong spillover effects across developed and emerging countries. The globalisation of the financial markets and the emergence of securitisation has enabled the transmission of shocks on the underlying real estate markets through liquid vehicles, such as mortgage backed securities (MBSs) and stocks of listed real estate companies such as Real Estate Investment Trusts (REITs). The risk stemming from an exposure to the US real estate market is not anymore seen as a standalone risk which as the traditional asset pricing theories imply can be diversified away if holding enough assets in the portfolio. It can have systemic implications affecting asset prices across the world undermining the diversification benefits of a global REIT portfolio.

Cross-market interdependence for REITs has been intensively investigated by previous literature. Some of the literature investigates the excess correlation triggered by the exposure to global or regional markets using an international CAPM model (e.g. Milunovich and Trück, 2013). Some studies assess the change in the correlation in excess returns or volatilities between markets (e.g. Gerlach et al., 2006; Bond et al., 2006; Fry et al., 2010; Hoesli and Reka, 2013; Change and Chen, 2014). However, the comovements stemming from the interconnectedness across markets have largely been ignored in the REIT literature. This paper fills the gap in the literature by investigating the spillover risks which may result in contagion due to the interconnectedness between REIT markets. We follow Milcheva and Zhu (2018) and estimate a Spatial Multi-Factor Model (SMFM) in order to disentangle spillover risk across assets which may be associated with spillover risks. While equilibrium spatial models can explain how real estate markets are connected using measures of spatial proximity, such as geographic distance, they abstract from the stochastic nature of real estate returns, the demand for real estate stemming from investors and the associated risk premiums included in the real estate prices. In turn, in the investment literature asset pricing models have been widely used to theoretically determine the required rate of return given the asset's non-diversifiable risk but does not take into account the spatial dynamics. Returns have therefore been modelled either in a purely spatial context in order to capture the co-movement across regions or in a purely asset pricing context to account for the asset's systematic risk. We consider a variety of bilateral linkages, such as trade flows, geographic distance, cultural similarities, cross-border bank exposure, foreign direct investment (FDI), portfolio investment, interest rate convergence and inflation convergence.

The SMFM is estimated at the national level for real estate stock indices for 14 developed countries. The model is estimated as a panel at a rolling window basis using Bayesian techniques. We find that spillover risks dramatically increase during the GFC and explain up to $60 \%$ of total real estate 
asset risk. In the rest of the time, idiosyncratic risks have been the predominant type of risk for real estate stocks.

Our results show that economic integration plays a more prominent role in the interconnectedness among markets than traditional linkages such as geographic distance. The results have important implications for real estate investors showing that conventional geographic diversification strategy in international REITs markets may not be sufficient during volatile periods as spillovers can propagate via a number of channels and investors need to take those into account too.

In addition, using the SMFM method we are able to disentangle the increase in the proportion of the return correlation which is due to spillover risk generated through the cross-border linkages between individual markets. Our paper provides empirical evidence that the rise in correlation is largely associated with the increase of spillover risk. This finding implies that by carefully selecting the most 'distant' markets based on bilateral investment exposures investors can reduce the risk exposure during volatile periods. Furthermore, residual linkages between country indices need to be accounted for as a means of assessing the diversification benefits of a global portfolio.

The rest of the paper is presented as follows. Section 2 provides a review of related research on this topic; Section 3 describes the model and data; the results are discussed Section 4 followed by concluding remarks in Section 5.

\section{Literature review}

With regards to the application of traditional asset pricing models, previous research has looked into explaining how risk should be managed in real estate portfolios (Blundell (2007), Crosby et al. (2016)) separately looking at systematic risks (Liow (2006), MacGregor and Schwann (2011)) and idiosyncratic risks (Chiang (2010), Akinsomi et al. (2013)). Crosby et al. (2016) look in addition to macro risks also at asset level risks by accounting for information contained in individual property transactions such as submarket quality and tenant covenants. Blundell et al. (2005) also look at risk in property portfolios splitting it into fundamental drivers of risk and modulators that lower or increase the variance triggered by the fundamentals. In terms of the idiosyncratic risk, Chiang (2010) finds that it is related to the vintage of the REIT and excess returns.

In addition to systematic and idiosyncratic risks, contagion has also received great attention. There is vast literature on the spillover effects associated with contagion and financial imbalances during the global financial crisis. Claessens and Forbes (2001) summarise the literature on contagion and volatility spillovers. Forbes and Rigobon (2002) argue that it is important to differentiate between interdependence and contagion. They use the term interdependence instead of contagion to measure the co-movement of returns across countries as they show that once they account for market volatility of correlation coefficients there is almost no increase in the correlation coefficients. Anton and Polk (2014) refer to contagion as a sudden increase in correlations across 
assets not explained by fundamentals. They look at firm level stock returns and show that contagion results from ownership-based connections across stocks and increases during crisis periods. Bekaert et al. (2014) explore how the global crisis led to an equity market contagion. They distinguish between domestic, US and global contagion implying an increase in the co-movement of the domestic asset portfolio with domestic, US-specific or global factors. They find contagion effects from the US stock market through trade exposure with US return fluctuations affecting the stock market performance of its trade partners.

Although the definition of contagion is arbitrary, the idea is that contagion emerges from changes in a single asset that become widespread in the cross-sectional dimension. ${ }^{1}$ Therefore, we refer to contagion as the increased spillover effects through the market and the idiosyncratic component triggered by an asset specific event. Most of the literature studies the contagion from equity markets to REIT markets. For instance, Kallberg et al. (2002) find significant increase in the synchronous regime shifts between real estate and equities across countries in bear markets. Bond et al., (2006) show significant increase in the correlation among property markets in Australia, Hong Kong, Japan and Singapore during the 1997 Asian crisis. Hoesli and Reka (2012) examine comovements, contagion and volatility spillovers in securitized real estate markets in the US, UK and Australia using time series analysis. They find strong volatility spillover effects between stock and securitized real estate markets in the US. Contagion effects are found only between US and UK REIT stocks. Using an international CAPM model with a GARCH process, Milunovich and Trück (2013) investigate the contagion between 11 REITs and equity markets during the GFC. They find statistically significant excess correlations between national REITs and regional and world real estate markets during the entire sample period, while there is only limited evidence to suggest that the correlation amongst REIT markets has increased during the GFC. Using Markov switching model, Chan et al. (2011) find evidence of flight to quality from stocks to treasury bonds and contagion between stocks, oil and real estate assets during crisis periods.

\section{Methodology}

We estimate an asset pricing model including a spatial term. The concept developed in spatial econometrics is to capture the effect of a shock at a specific point in space on another place (i.e. Haining (2003)). However, proximity does not need to be measured in terms of physical space. It can be defined by using other types of distance metrics in the broader sense, such as economic, political or social similarity. Fernandez (2011) proposes a Spatial Capital Asset Pricing (SCAPM) model, and shows the implications of spatial autocorrelation in asset returns for risk management by deriving a value at risk from the SCAPM formulation. Eder and Keiler (2015) also use a SCAPM model. They decompose the credit spread into a spillover risk premium, a systematic risk premium, and an idiosyncratic risk premium. Pesaran and Tosetti (2011) expand Forni and Lippi

\footnotetext{
${ }^{1}$ De Bandt and Hartmann (2000) discuss the literature on systemic risks and conclude that contagion is at their heart defining it as "a particularly strong propagation of failures from one institution, market or system to another". Bekaert et al. (2014) refer to contagion as to "unexpected increases in factor loadings and residual correlations".
} 
(2001) dynamic factor model and propose that asset returns can exhibit both weak and strong crosssectional dependencies across returns. The strongly dependent part of the asset returns can only be diversified away when the portfolios are constructed using factor loadings as weights. In addition to the strong dependence, the weak dependence can arise due to the interconnectedness of each pair of assets. Portfolios with weakly dependent returns can fully diversify them away by using weights in the portfolio construction to capture the weak dependence in the returns. Milcheva and Zhu (2018) estimate a Spatial Factor Model applied to REITs for the first time. They argue that as the underlying assets of REITs are fixed in location, these firms which own properties located close to each other may exhibit stronger comovement in their performance. This comovement cannot be fully captured by the similarity in market risk exposure. The results show that the inclusion of a spatial component matters and improves the model fit in each market.

\subsection{MFM and SMFM}

In finance, the MFM is widely used to determine a theoretically appropriate required excess rate of return of an asset from the risk-free rate, if that asset is to be added to an already well-diversified portfolio, given the asset's sensitivity to the market risk, represented by $\bar{\beta}_{i}$ and the expected excess return of the market. The MFM is given by:

$\tilde{r}_{i, t}=\bar{\alpha}_{\imath}+\bar{\beta}_{i} \tilde{r}_{t}^{M}+u_{i, t}$

with $\tilde{r}_{i, t}$, the excess return of asset $i$ in period $t$ calculated as $\tilde{r}_{i, t}=r_{i, t}-r_{t}^{f}, r_{t}^{f}$ is the risk-free rate in period $t, \tilde{r}_{t}^{M}$, the excess market return given by $\tilde{r}_{t}^{M}=r_{t}^{M}-r_{t}^{r f}$, and $u_{i, t}$ is the error term with $u_{i, t} \sim N\left(0, v_{i}^{2}\right)$.

Under the assumption of $\operatorname{cov}\left(\tilde{r}_{t}^{M}, u_{i, t}\right)=0$, we have for the variance of the asset vector:

$\Sigma=\bar{\beta} \Psi \bar{\beta}^{\prime}+\Omega$,

where $\Sigma$ is the covariance matrix of the returns, $\Omega$ is the covariance matrix of error terms. $\Psi$ is the covariance matrix of the common factors with $\Psi=\mathrm{E}\left[\left(\tilde{r}_{t}^{M}-\mathrm{E}\left(\tilde{r}_{t}^{M}\right)\right)\left(\tilde{r}_{t}^{M}-\mathrm{E}\left(\tilde{r}_{t}^{M}\right)\right)^{\prime}\right]$. From (4) we can see that the asset variance can be decomposed into a systematic part $\left(\bar{\beta} \Psi \bar{\beta}^{\prime}\right)$ which depends on the asset sensitivity to the market and the market variance, and an idiosyncratic part $(\Omega)$ which depends on the variance of the residuals.

The traditional MFM accounts for co-movements between each two assets indirectly through the relationship of each asset with the market. Moreover, the MFM assumes that the residuals are not correlated across time and across the assets. However, we have seen that during crisis periods a shock which is assumed to be idiosyncratic in nature and to have no systematic implications in a well-diversified portfolio can actually trigger spillover risk. This can happen through different channels due to illiquidity, portfolio rebalancing, herding behavior, etc. To capture the spillovers 
of asset's idiosyncratic risk we incorporate a spatial term which explicitly accounts for the linkages across the assets. The SMFM is given by:

$\tilde{r}_{i, t}=\alpha_{i}+\rho \sum_{j=1, j \neq i}^{N} w_{t, j, i} \tilde{r}_{i, t}+\beta_{i} \tilde{r}_{t}^{M}+e_{i, t}$

where $w_{t, j, i}$ captures the 'distance' between each two countries in period $t$, and $w_{t, j, i}=0$ for $i=j$ for country $i$ and $j$. We use time-varying weights since shifts in the weights can have implications on the estimated coefficients. $\sum_{j=1, j \neq i}^{N} w_{t, j, i} \tilde{r}_{i, t}$ is the weighted sum of the contemporaneous excess returns between each two country portfolios in period $t . \rho$ is the spatial autoregressive parameter capturing the comovement effects between the portfolio returns. We allow for heteroskedastic error terms with $e_{i, t} \sim N\left(0, \sigma_{i}^{2}\right)$. Kou et al. (2015) derive asset pricing models including a spatial component which characterize how spatial linkages affect expected portfolio returns under market equilibrium. They show that if each investor holds a mean-variance efficient portfolio, in equilibrium, the market return in the SMFM will be mean-variance efficient and every investor will hold a combination of the market portfolio and the risk-free asset.

Equation (2) can also be expressed in a matrix form such as:

$\left[\begin{array}{c}\tilde{r}_{1, t} \\ \tilde{r}_{2, t} \\ \vdots \\ \tilde{r}_{N, t}\end{array}\right]=\left[\begin{array}{c}\alpha_{1} \\ \alpha_{2} \\ \vdots \\ \alpha_{N}\end{array}\right]+\rho\left[\begin{array}{cccc}0 & w_{t, 1,2} & \cdots & w_{t, 1, N} \\ w_{t, 2,1} & 0 & \ldots & w_{t, 2, N} \\ \vdots & \vdots & \ddots & \vdots \\ w_{t, N, 1} & w_{t, N, 2} & \cdots & w_{t, N, N}\end{array}\right]\left[\begin{array}{c}\tilde{r}_{1, t} \\ \tilde{r}_{2, t} \\ \vdots \\ \tilde{r}_{N, t}\end{array}\right]+\tilde{r}_{t}^{M}\left[\begin{array}{c}\beta_{1} \\ \beta_{2} \\ \vdots \\ \beta_{N}\end{array}\right]+\left[\begin{array}{c}e_{1} \\ e_{2} \\ \vdots \\ e_{N}\end{array}\right]$

with $w_{t, 1,2}$ being the weight calculated from the distance between country 1 and 2 in period $t$. Because of the standardization of the weight matrix described in Section 4.3, $w_{t, 1,2}$ is not necessarily equal to $w_{t, 2,1}$, so that the weight matrix can be asymmetric. Equation (4) can be expressed as:

$\tilde{r}_{t}=\alpha+\rho W_{t} \tilde{r}_{t}+\beta \tilde{r}_{t}^{M}+e_{t}$

$\tilde{r}_{t}$ denotes the vector of excess returns of the $N$ portfolios in period $t$ and $\tilde{r}_{t}^{M}$ is the value of the global market return, which is the same for each dependent variable. $W_{t}$ is the standardized $N \times N$ non-stochastic spatial dependence weight matrix with zeros in the diagonal terms and non-zeros in the off-diagonal terms. $\alpha$ is an $N \times 1$ coefficient vector of the individual portfolio alphas. $\beta$ is a $N \times 1$ vector, with elements representing the portfolio betas, and $\beta=\left(\beta_{1}, \beta_{2}, \ldots, \beta_{N}\right)^{\prime} . e_{t}$ is an $N$ $\times 1$ vector of error terms.

Since the SMFM in Equation (5) has the dependent variable both on the left and right hand side, 
in order to estimate it we need to use its reduced form. The reduced form is given as:

$\tilde{r}_{t}=\left(I-\rho W_{t}\right)^{-1}\left[\alpha+\beta \tilde{r}_{t}^{M}+e_{t}\right]$

We define $\left(I-\rho W_{t}\right)^{-1}=V_{t}$ so that Equation (5) can be rewritten as:

$\tilde{r}_{t}=V_{t} \alpha+V_{t} \beta \tilde{r}_{t}^{M}+V_{t} e_{t}$

Since $V_{t}=\left(I-\rho W_{t}\right)^{-1}=I+\rho W_{t}+\rho^{2} W_{t}^{2}+\rho^{3} W_{t}^{3}+\cdots$, Equation (9) implies a spatial multiplier effect on the asset excess returns (see Anselin (2006) and LeSage and Pace (2009)). Any changes in the returns in one country will also affect the remaining countries through the spatial linkages among the countries. Not only the 'first order neighbours', $\rho W_{t}$, get affected, but also 'neighbour's neighbours' are impacted through the spatial multiplier effect, $\rho^{2} W_{t}^{2}, \rho^{3} W_{t}^{3}$, etc. In the end, the shock can have a feedback effect on the country of origin of the shock.

\subsection{Variance Decomposition}

Kou et al., (2015) show that, in equilibrium, under the assumption of $\operatorname{cov}\left(\tilde{r}_{t}^{M}, e_{t}\right)=0$, so

$\beta=\left(I-\rho W_{t}\right) \frac{\operatorname{cov}\left(\tilde{r}_{t}, \tilde{r}_{t}^{M}\right)}{\operatorname{var}\left(\tilde{r}_{t}^{M}\right)}=\left(I-\rho W_{t}\right) \bar{\beta}$,

which implies the sensitivity between the asset return and the market also depends on the degree of spatial interaction $V$ :

$\bar{\beta}=E\left[\frac{\operatorname{cov}\left(\tilde{r}_{t}, \tilde{r}_{t}^{M}\right)}{\operatorname{var}\left(\tilde{r}_{t}^{M}\right)}\right]=E\left(V_{t} \beta\right)=\bar{V} \beta=\beta+\rho \bar{W} \beta+\rho^{2} \bar{W}^{2} \beta^{2}+\rho^{3} \bar{W}^{3} \beta^{3}+\cdots$

Where $\bar{V}=\frac{1}{T} \sum_{t=1}^{T} V_{t}$ and $\bar{W}=\frac{1}{T} \sum_{t=1}^{T} W_{t}$. Based on the MFM, $\bar{\beta}$ captures the correlation between assets. Equations (8) and (9) imply that the covariance to the market risk can come from two aspects. The first part is based on the exposure to market risk $(\beta)$, which reflects the systematic risk. The second part is also built upon the interconnectedness between assets $\left(\rho \bar{W} \beta+\rho^{2} \bar{W}^{2} \beta^{2}+\right.$ $\left.\rho^{3} \bar{W}^{3} \beta^{3}+\cdots\right)$. The covariance with the market risk can also be affected by the covariance of its neighbours $(\rho \bar{W} \beta)$, and even neighbours' neighbours $\left(\rho^{2} \bar{W}^{2} \beta^{2}+\rho^{3} \bar{W}^{3} \beta^{3}+\cdots\right)$.

In the factor model, the variance of the returns can be decomposed into the market risk and the idiosyncratic risk. In the SMFM, the variance of returns can be decomposed into market risk, idiosyncratic risk and spillover risk such as

$\Sigma=\bar{V} \beta \Psi \beta^{\prime} \bar{V}^{\prime}+\bar{V} \Omega \bar{V}^{\prime}$, 
where $\Sigma$ is the covariance matrix of the returns which is the same as the covariance in the factor model. $\Xi$ is the covariance matrix of the error terms in the spatial factor model. $\beta \Psi \beta^{\prime}$ captures the part of the market risk that is uncorrelated with the linkages between assets, and the rest $\left(\bar{V} \beta \Psi \beta^{\prime} \bar{V}^{\prime}-\beta \Psi \beta^{\prime}\right)$ is built upon the linkages between assets.

We estimate the SMFM including three other factors next to the market return similar to Fama and French (2012) accounting for the size, value and momentum in stock returns. In order to account for changes in the coefficients across time, we estimate Equation (3) using a rolling window of 36 months. In doing so, we obtain an alpha and a beta for each portfolio and each month as well as a spatial coefficient for each month. With regards to the estimation, we use Bayesian estimation with heteroskedastic error terms following LeSage (1997 and 2003). ${ }^{2}$

\subsection{The spatial weight matrix}

The spatial weight matrix plays a crucial role in spatial econometric models because the estimated spatial correlation depends on the specification of the weight matrix. The weight matrix is originally constructed using the geographic distance between two entities. For instance, Holly et al. (2011) analyze the spatial and temporal diffusion of house price shocks across UK regions. They find that a shock to London's house prices has a significant contemporaneous effect on all other regions, with the size of the effect depending on the commuting distance of the region from London. However, recent research shows that the physical distance may not be the best way to account for spatial co-movements. Indeed, measures of 'economic or financial distance' have been introduced in an attempt to deal with the cross-sectional dependence of economic variables (see Conley and Topa, 2002; Zhu et al., 2013). Bekaert et al. (2014) explore how the global crisis led to an equity market contagion. They find contagion effects from the US stock market through trade exposure with US return fluctuations affecting the stock market performance of its trade partners. Asgharian et al. (2013) compare several measures of spatial proximity to find that bilateral trade best captures the international co-movements on the stock markets. Milcheva and Zhu (2015) find that bank integration can better capture house price co-movements than other measures of economic integration.

In this paper, we consider three types of interconnection between countries. The first category is investment exposure, including bank exposure, trade exposure, foreign direct investment (FDI) and foreign portfolio exposure. Countries that are more integrated globally through trade or other investment activities will experience stronger co-movements in REITs performance. For instance, trade and FDI exposure can foster business cycle synchronization across countries, thereby affecting the cross-country dependence through demand and supply side channels (Beine et al., 2010; Wälti, 2010; Asgharian et al., 2013, Bekaert et al., 2014 and Milcheva and Zhu, 2015). If portfolio investment between two countries increases, real estate price co-movements can increase

\footnotetext{
${ }^{2}$ We prefer Bayesian estimation over Maximum Likelihood (ML) estimation due to problems resulting from the low degrees of freedom associated with the heteroscedastic error terms when using ML estimation.
} 
due to stronger indirect demand from foreign investors through the purchase of real estate stocks or investment in equity funds (Eickmeier and $\mathrm{Ng}, 2011$ ). High level of financial integration via cross-border banking exposure can also transfer capital across countries through the international banking system, which can affect the credit supply to the domestic market, and therefore influence the demand and supply in the domestic market (Bruno and Shin, 2014; Milcheva and Zhu, 2015). Data for the trade matrix comes from the Trade Statistics of the OECD. Bilateral FDI flows are from the Foreign Direct Investment Statistics of the OECD. For bank balance-sheet exposure we use bilateral bank claims based on the consolidated bank statistics of the BIS using Table 9B.

The second category of interconnection is based on the similarity in the economic or financial development. We consider inflation convergence and interest rate convergence. Transmission occurs when the existence of purchasing power parity (PPP) induces investors to try to hedge domestic assets with foreign real estate since inflation differences among those countries do not exist (see Cooper and Kaplanis, 1994). Similarly, the co-movement across returns in countries with high interest rate convergence can be explained by arbitrage-free conditions leading to more efficient capital relocation (see Marston, 1997 and Asgharian et al., 2013).

The third category is related to the entrance barrier to the local market, including distance, cultural similarity and openness. Portes and Rey (2005) show that geographic distance presents a barrier to international equity flows. Cultural similarity assesses a range of indicators such as the degree of the society to embrace entrepreneurial risk, etc. To measure cultural similarities, we use the Hofstede scores from the Hofstede website ${ }^{3}$. We also measure distance in terms of openness using data from the Heritage Foundation and accounting for both trade and investment openness.

We follow Asgharian et al. (2013) and Milcheva and Zhu (2015), and construct the weight based on the nine linkages mentioned above. The Appendix provides detailed formulas for the construction of the weights ${ }^{4}$.

\subsection{Data}

Our estimation sample includes the following 14 countries - Australia, Belgium, Canada, Finland, France, Germany, Italy, Japan, the Netherlands, Spain, Sweden, Switzerland, UK and the US since they have sufficiently long time series data for listed real estate company returns. The estimation uses monthly data and the estimation period ranges from 1993M1 to 2015M3. The dependent variable is the monthly log-difference of the FTSE EPRA/NAREIT index capturing the performance of listed real estate companies in each country. The national indices are taken from the European Public Real Estate Association (EPRA) representing Europe's publicly listed property companies and tracking the performance of companies engaged in the ownership, trading

\footnotetext{
${ }^{3}$ https://www.geert-hofstede.com/

${ }_{4}^{4}$ In addition, details on the construction of the weight matrices are documented in Milcheva and Zhu (2015).
} 
and development of income-producing real estate. The fundamental business of those listed real estate companies is investing in and operating real estate assets, with income being generated from renting these assets to other organizations. Table 1 shows the descriptive statistics of the indices of the listed property companies in each country. Listed real estate firms in Sweden achieved the highest return over the period between 1993 and 2015. Spanish real estate firms showed the lowest return and highest volatility, due to crash in the real estate market in Spain following the GFC. The real estate firms in France and the Netherlands have the highest correlation in their returns, amounting to $87.4 \%$. Firms in Spain and Japan show the lowest correlation of only $10 \%$.

Table 1: Descriptive Statistics

Dependent variable: listed real estate index returns at country level

\begin{tabular}{|c|c|c|c|c|c|c|c|c|c|c|c|c|c|c|}
\hline $\begin{array}{l}\text { Real } \\
\text { estate } \\
\text { return }\end{array}$ & $\mathbf{A U}$ & BE & $\mathbf{C A}$ & FI & FR & $\mathbf{D E}$ & IT & $\mathbf{J P}$ & NL & ES & SE & $\mathbf{C H}$ & UK & US \\
\hline Mean & 0.008 & 0.006 & 0.008 & 0.009 & 0.010 & 0.003 & 0.003 & 0.005 & 0.007 & -0.009 & 0.011 & 0.009 & 0.006 & 0.009 \\
\hline Std & 0.052 & 0.038 & 0.052 & 0.091 & 0.053 & 0.066 & 0.082 & 0.070 & 0.051 & 0.153 & 0.067 & 0.040 & 0.056 & 0.050 \\
\hline Max & 0.151 & 0.111 & 0.155 & 0.371 & 0.178 & 0.246 & 0.260 & 0.224 & 0.198 & 1.154 & 0.240 & 0.156 & 0.272 & 0.208 \\
\hline Min & -0.380 & -0.237 & -0.394 & -0.432 & -0.283 & -0.445 & -0.496 & -0.207 & -0.260 & -0.806 & -0.333 & -0.170 & -0.286 & -0.334 \\
\hline \multicolumn{15}{|c|}{ Correlation } \\
\hline \multicolumn{15}{|l|}{$\mathrm{AU}$} \\
\hline $\mathrm{BE}$ & 0.597 & & & & & & & & & & & & & \\
\hline CA & 0.706 & 0.518 & & & & & & & & & & & & \\
\hline FI & 0.492 & 0.533 & 0.485 & & & & & & & & & & & \\
\hline FR & 0.666 & 0.777 & 0.595 & 0.641 & & & & & & & & & & \\
\hline $\mathrm{DE}$ & 0.584 & 0.624 & 0.544 & 0.481 & 0.697 & & & & & & & & & \\
\hline IT & 0.510 & 0.550 & 0.556 & 0.498 & 0.646 & 0.598 & & & & & & & & \\
\hline JP & 0.479 & 0.279 & 0.426 & 0.307 & 0.371 & 0.317 & 0.321 & & & & & & & \\
\hline NL & 0.692 & 0.789 & 0.617 & 0.659 & 0.874 & 0.681 & 0.656 & 0.403 & & & & & & \\
\hline ES & 0.230 & 0.292 & 0.193 & 0.224 & 0.294 & 0.202 & 0.348 & 0.100 & 0.283 & & & & & \\
\hline SE & 0.558 & 0.576 & 0.518 & 0.546 & 0.677 & 0.548 & 0.541 & 0.350 & 0.661 & 0.223 & & & & \\
\hline $\mathrm{CH}$ & 0.527 & 0.687 & 0.423 & 0.547 & 0.713 & 0.568 & 0.460 & 0.296 & 0.686 & 0.197 & 0.511 & & & \\
\hline UK & 0.656 & 0.610 & 0.592 & 0.593 & 0.720 & 0.614 & 0.531 & 0.412 & 0.737 & 0.204 & 0.595 & 0.602 & & \\
\hline US & 0.720 & 0.546 & 0.795 & 0.542 & 0.630 & 0.549 & 0.512 & 0.409 & 0.676 & 0.153 & 0.606 & 0.475 & 0.689 & \\
\hline
\end{tabular}

Explanatory variables

\begin{tabular}{lcrrrrrr}
\hline & $\begin{array}{l}\text { Global } \\
\text { market } \\
\text { return }\end{array}$ & SMB & HML & WML & $\begin{array}{l}\text { Risk- } \\
\text { free } \\
\text { rate }\end{array}$ & $\begin{array}{l}\text { Global } \\
\text { listed } \\
\text { real } \\
\text { estate } \\
\text { return }\end{array}$ & $\begin{array}{l}\text { Global } \\
\text { direct } \\
\text { real } \\
\text { estate } \\
\text { return }\end{array}$ \\
\hline Mean & 0.005 & 0.001 & 0.003 & 0.003 & 0.002 & 0.004 & 0.007 \\
Std & 0.043 & 0.020 & 0.024 & 0.015 & 0.002 & 0.058 & 0.061 \\
Max & 0.115 & 0.080 & 0.117 & 0.061 & 0.006 & 0.183 & 0.120 \\
Min & -0.195 & -0.084 & -0.095 & -0.054 & 0.000 & -0.326 & -0.030 \\
\hline Correlation & with & dependent & variable & & & & \\
\hline AU & 0.544 & 0.120 & 0.089 & -0.143 & 0.026 & 0.530 & 0.199 \\
BE1 & 0.416 & 0.134 & 0.162 & -0.130 & -0.060 & 0.321 & 0.010
\end{tabular}




\begin{tabular}{lrrrrrrr} 
CA & 0.408 & 0.192 & 0.209 & -0.047 & -0.015 & 0.577 & 0.077 \\
FI & 0.345 & 0.204 & 0.191 & -0.104 & -0.019 & 0.428 & 0.015 \\
FR & 0.491 & 0.196 & 0.183 & -0.141 & -0.024 & 0.451 & 0.051 \\
DE & 0.430 & 0.186 & 0.080 & -0.141 & -0.050 & 0.370 & 0.144 \\
IT & 0.428 & 0.145 & 0.080 & -0.119 & 0.004 & 0.361 & 0.174 \\
JP & 0.380 & 0.176 & 0.172 & -0.176 & -0.030 & 0.382 & 0.055 \\
NL & 0.513 & 0.155 & 0.188 & -0.134 & -0.011 & 0.483 & 0.057 \\
ES & 0.182 & 0.011 & 0.104 & -0.044 & 0.096 & 0.136 & 0.274 \\
SE & 0.465 & 0.188 & 0.124 & -0.185 & -0.065 & 0.360 & 0.048 \\
CH & 0.401 & 0.106 & 0.158 & -0.086 & -0.032 & 0.301 & -0.016 \\
UK & 0.471 & 0.143 & 0.261 & -0.147 & 0.007 & 0.514 & 0.124 \\
US & 0.444 & 0.197 & 0.202 & -0.125 & 0.004 & 0.576 & 0.084 \\
\hline
\end{tabular}

The explanatory variables are the four factors used in Fama and French (2012) and are obtained from Ken French's website ${ }^{56}$. The four factors include a global market return index, the difference between the returns on diversified portfolios of small stocks and big stocks (SMB), the difference between the returns on diversified portfolios of high book-to-market (value) stocks low book-tomarket (growth) stocks (HML), and the difference between the month $t$ returns on diversified portfolios of the winners and losers of the past year (WML). As we are dealing with country-level data, we use the global factors for developed markets. The descriptive statistics for all variables are reported in Table 1. The average monthly return of the market index over the sample period is $0.5 \%$ compared to a risk-free rate of $0.2 \%$. The return of the global listed real estate index is also $0.4 \%$ which is considerably lower than the return of the underlying market - the global direct commercial real estate index of $0.7 \%$ based on valuations. The risk of investing in direct real estate is highest with a standard deviation of $6.1 \%$ followed by listed real estate, $5.8 \%$, and the risk of the market of $4.3 \%$. Regarding the listed real estate index, we observe some variation across the selected countries with the lowest average returns in Spain with $-0.9 \%$ and the highest in France with $1 \%$. The highest correlation in returns is observed between the Netherlands and France (87.4\%) followed by the US and Canada (79.5\%), and the lowest is between Japan and the Netherlands (10\%).

\section{Results}

\subsection{The SMFM versus the MFM}

Table 2 shows the results using different weight matrices. The spatial coefficient ranges between 0.640 and 0.717 , which is smaller to what has been reported in previous studies regarding stock comovement using a spatial econometrics model as well as different types of weight matrices (Fernandez (2011), Asgharian et al. (2013)). Asgharian et al. (2013) use different weight matrices and report coefficients between 0.81 and 0.83 . However, their study and the majority of the articles

\footnotetext{
${ }^{5}$ See http://mba.tuck.dartmouth.edu/pages/faculty/ken.french/

${ }^{6}$ Variations in the factors of the factor models lead to robust conclusions regarding the significance of the spatial term and the systemic, systematic and idiosyncratic risks.
} 
on spatial linkages estimate a spatial model and not a spatial factor model. Fernandez (2011) estimates what an SMFM, however, she uses a different methodology. Instead of the Fama and French factors, she constructs weight matrices to capture the returns of BMS, HML and WML portfolios. She reports spatial coefficients between 0.77 and 0.86 based on a sample of 126 firms in Latin America. The smaller spatial coefficient reported in our study can be due to the nature of underlying direct real estate assets which those listed firms hold, which are less liquid and more heterogeneous.

The significance of our coefficients means that it is important to account for spatial linkages across real estate firms as it affects the performance of individual companies through different channels. By adding the spatial component, the R-squared increases by 16 percent, from 0.21 to 0.37 . We can see from the Bayesian Information Criterion (BIC) that the SMFM using any of the weight matrices is preferred to the MFM which has a BIC of -1.808 . Table 1 also reports the average absolute value of the intercept, or the model alpha, which is the average of the absolute alphas of the 14 country indices. In addition to the alpha, we include its average standard error and a GRS F-test by Gibbons et al. (1989) for the joint significance of the individual alphas. As expected, the average absolute value of alpha decreases in the SMFM due to the inclusion of an additional variable that can explain part of the return variations. The standard error of the intercept is also smaller in the SMFM. In the SMFM, the GRS test value is smaller in both economic and statistic magnitude. However, it should be noted that as only over $20 \%$ of the variance is explained, the GRS test may lack the power, which implies that the significance of the GRS test may be underestimated in the MFM model. When the spatial term is added, the standard error of the GRS test decreases by a half. With the improvement of the predictive accuracy, the 'bad model' problem (Fama and French, 2012) can be relieved to some degree.

\section{Table 2: SMFM with alternative weight matrices}

Note: The model is estimated from 1993M1 to 2015M3. The dependent variable is the log difference of the excess listed property index for each country in each month. $\rho$ is the coefficient for spatial dependence. Std $(\rho)$ is the standard deviation of $\rho . R 2$ is the average coefficient of determination in the panel model. BIC stands for the Bayesian Information Criteria. $|\alpha|$ stands for the absolute mean of the individual alphas. Std $(\alpha)$ stands for the average standard deviation of alpha. The GRS is a test for the joint significance of the portfolio alphas. With 14 portfolios and 324 monthly returns, the critical values for the GRS test for all models are 1.53, 1.72 and 2.14 for 10\%, 5\% and 1\% significance level, respectively.

\begin{tabular}{lccccccc}
\hline & $\rho$ & $\operatorname{Std}(\rho)$ & $\mathrm{R} 2$ & $\mathrm{BIC}$ & $|\alpha|$ & $\mathrm{Std}(\alpha)$ & GRS \\
\hline SMFM & & & & & & & \\
Trade & $0.663^{* * *}$ & 0.012 & 0.375 & -3.100 & 0.003 & 0.002 & 1.226 \\
Bank Flow & $0.686^{* * *}$ & 0.011 & 0.364 & -3.088 & 0.003 & 0.002 & 1.270 \\
Portfolio investment & $0.688^{* * *}$ & 0.011 & 0.374 & -3.103 & 0.003 & 0.002 & 1.225 \\
FDI & $0.717^{* * *}$ & 0.011 & 0.377 & -3.113 & 0.003 & 0.002 & 1.225 \\
Interest rate convergence & $0.641^{* * *}$ & 0.013 & 0.356 & -3.076 & 0.003 & 0.002 & 1.243 \\
Inflation convergence & $0.642^{* * *}$ & 0.012 & 0.355 & -3.073 & 0.003 & 0.002 & 1.173 \\
Cultural Similarity & $0.640^{* * *}$ & 0.012 & 0.346 & -3.047 & 0.003 & 0.002 & 1.164 \\
\hline
\end{tabular}




\begin{tabular}{lllllllc}
\hline Openness Similarity & $0.645^{* * *}$ & 0.014 & 0.352 & -3.054 & 0.003 & 0.002 & 1.141 \\
Geographic distance & $0.638^{* * *}$ & 0.012 & 0.357 & -3.090 & 0.003 & 0.002 & 1.154 \\
MFM & & & 0.215 & -1.808 & 0.004 & 0.004 & $1.548^{*}$ \\
\hline
\end{tabular}

The results in Table 2 show that most weight matrices using measures of financial, trade and investment integration do a good job in capturing the spatial correlation across the country returns. Bilateral exposure plays a more important role in channelling the comovement. One reason could be that the global shocks are the dominant factors for the co-movements of the returns, so the cross-sectional correlation between market returns is predominantly caused by strong global comovements of the returns. If this is the case, the estimated values of $\rho$ should be large, no matter how the relative weights in $\mathrm{W}$ are chosen. We follow Asgharian et al., (2013) and perform a simulation analysis to check whether the estimated value of $\rho$ is also economically significant. We randomly generate 200 spatial weights matrices and estimate the model for each matrix separately. This results in 200 different estimates of $\rho$. Figure 2 shows the $95 \%$ and $90 \%$ inter-percentile ranges of the empirical distribution of these estimates together with the estimated $\rho$ obtained when using our eight distance measures. As shown in Figure 2, the values of $\rho$ range in the $95 \%$ confidence interval between 0.66 and 0.64 . Our distance measures generally outperform the vast majority of randomly defined distance measures with CPI convergence, interest rate convergence, cultural similarity, openness similarity and distance being below the $95 \%$ confidence interval line and hence are economically insignificant. Therefore, for the further analysis we will only focus on the weight matrices which are economically significant, such as portfolio investment flows, bank claims, trade exposure and FDI exposure.

Figure 2: Spatial coefficient point estimates for various weight matrices and the empirical distribution of spatial coefficients from random matrices 


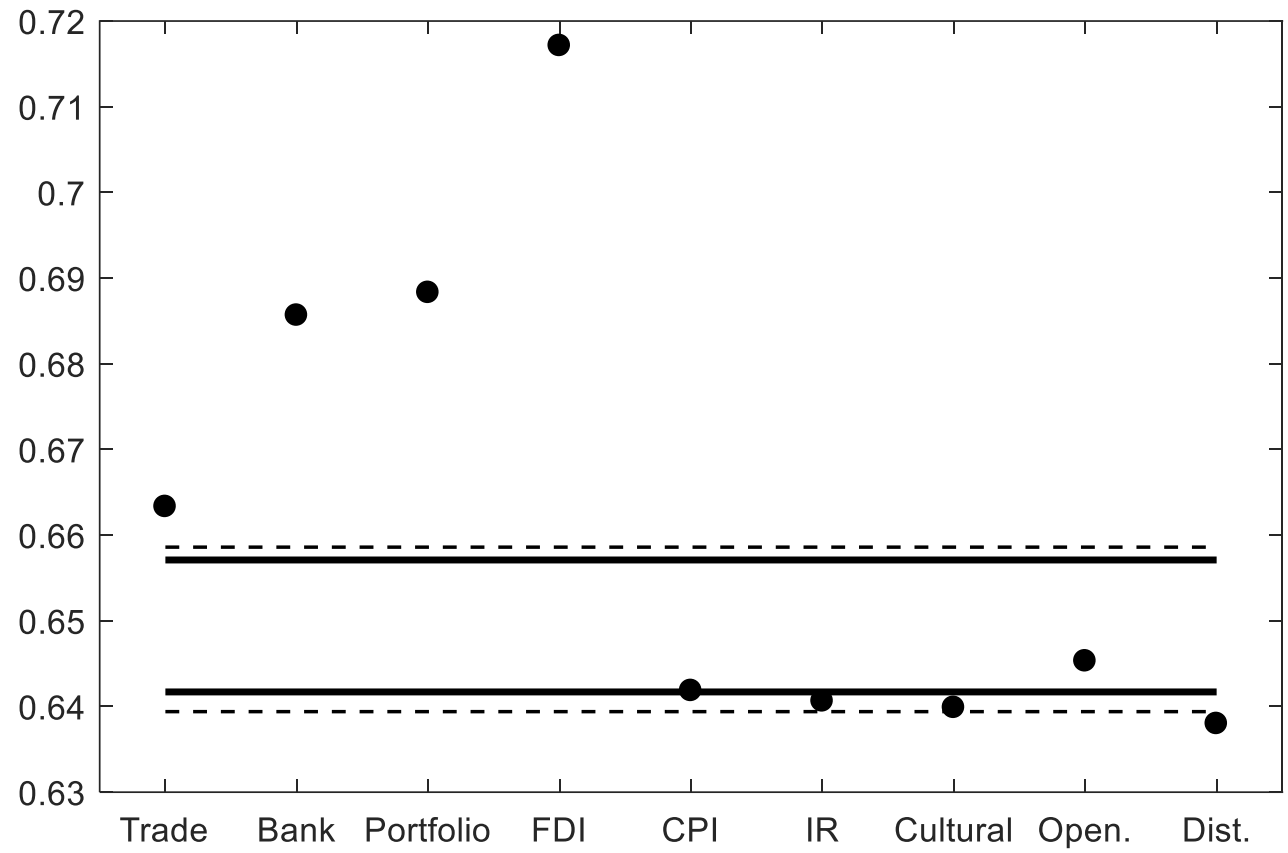

Note: This figure sets the point estimates of the spatial coefficients ( $\rho$ ) from a range of 'distance'measures against the 95\% and 90\% inter-percentile ranges for the empirical distribution of the estimated spatial coefficients from 200 randomly generated spatial weights matrices.

Using bilateral FDI as the weights, we show the difference in the coefficients for the Fama-French factors in MFM and SMFM, as reported in Table 3. UK has the highest market beta (0.731) amongst the three countries, while US exhibits the lowest beta (0.644). For the rest of the European countries, the average market beta is $0.7479^{7}$, which is also higher than US and Japan. These results align with the findings in Chen et al. (2015) who found that the European REIT market possessed the highest mean beta among seven REIT markets, indicating a relatively high systematic risk in this region.

However, when spatial dependence is considered, the coefficients for market beta fall by around two thirds in all three markets. The coefficients for the other factors also drop noticeably. The reason could be that part of the covariance of the asset return with the market is due to the underlying linkages between markets. Therefore, a good understanding on the channels of interconnectedness of markets can help investors to offset the comovement in the sensitivity to common risk to some degree.

Table 3: Coefficients of common factors for excess real estate returns in individual countries based on the MFM and SMFM

\footnotetext{
${ }^{7}$ Detailed results are available per request on authors.
} 
Note: The model is estimated from 1993M1 to 2015M12. The dependent variable is the log difference of the excess listed property index for each country in each month. Panel A is based on the MFM. Panel B is based on SMFM. The weight matrix used for the SMFM is based on the bilateral FDI. 95\% Bayesian confidence interval is reported in parentheses. SMB stays for returns of small minus big portfolios, HML - returns of high minus low book-to-market portfolios, WML - returns of winners minus losers portfolios capturing the momentum effects. Only the coefficients for Japan, UK and US are reported with the rest of the results available upon request.

\begin{tabular}{|c|c|c|c|c|c|}
\hline & Alpha & Beta & SMB & HML & WML \\
\hline \multicolumn{6}{|c|}{ Panel A: MFM } \\
\hline \multirow{2}{*}{$\mathbf{J P}$} & -0.005 & 0.692 & 0.712 & 0.671 & 0.073 \\
\hline & {$[-0.013 ; 0.004]$} & [0.492;0.892] & {$[0.314 ; 1.109]$} & {$[0.339 ; 1.003]$} & {$[-0.538 ; 0.683]$} \\
\hline \multirow{2}{*}{ UK } & -0.004 & 0.731 & 0.544 & 0.759 & 0.312 \\
\hline & {$[-0.012 ; 0.004]$} & {$[0.532 ; 0.931]$} & {$[0.146 ; 0.941]$} & {$[0.427 ; 1.091]$} & {$[-0.299 ; 0.922]$} \\
\hline \multirow[t]{2}{*}{ US } & -0.000 & 0.644 & 0.654 & 0.524 & 0.447 \\
\hline & {$[-0.008 ; 0.008]$} & {$[0.444 ; 0.844]$} & {$[0.257 ; 1.052]$} & {$[0.193 ; 0.856]$} & {$[-0.163 ; 1.058]$} \\
\hline \multicolumn{6}{|c|}{ Panel B: SMFM } \\
\hline \multirow{2}{*}{$\mathbf{J P}$} & -0.003 & 0.178 & 0.243 & 0.295 & -0.366 \\
\hline & {$[-0.008 ; 0.002]$} & {$[0.053 ; 0.301]$} & {$[0.002 ; 0.490]$} & {$[0.104 ; 0.493]$} & {$[-0.749 ; 0.029]$} \\
\hline \multirow[t]{2}{*}{ UK } & -0.001 & 0.203 & 0.086 & 0.289 & 0.011 \\
\hline & {$[-0.005 ; 0.003]$} & {$[0.095 ; 0.318]$} & {$[-0.123 ; 0.296]$} & {$[0.107 ; 0.467]$} & {$[-0.298 ; 0.343]$} \\
\hline \multirow[t]{2}{*}{ US } & 0.003 & 0.104 & 0.175 & 0.094 & 0.140 \\
\hline & {$[-0.001 ; 0.008]$} & {$[-0.011 ; 0.219]$} & {$[-0.033 ; 0.390]$} & {$[-0.091 ; 0.283]$} & {$[-0.187 ; 0.449]$} \\
\hline
\end{tabular}

We conduct robustness tests to account for global market factors specifically associated with the real estate market. We include either the global FTSE NAREIT/EPRA index representing the listed real estate sector or the global IPD index representing the direct commercial real estate sector which is the underlying asset in which listed real estate companies are invested. The results are presented in Panel A and Panel B in Table 4, respectively. When the factor associated with the real estate equity market is added, the spatial dependence coefficient slightly decreases to between 0.60 and 0.66 . The adjusted R-squared of the MFM rises from $21.5 \%$ in the baseline model to $28.5 \%$. When the direct real estate investment index is included the spatial coefficients remain similar to the baseline case in Table 2. The R-squared slightly increases by around 3 percentage points. Overall, there is no noticeable difference in the models with and without the real estate market index.

Fama and French (2012) conclude that using global factors may not be able to predict the returns in the local market when the assets are regionally integrated, resulting in the 'bad model' problem. Therefore, we follow Fama and French (2012) and include the regional factors instead. We include North American, Asian and European four factors as well as the listed real estate equity excess returns in the three regions. The results are reported in Panel $\mathrm{C}$ Table 4 . When regional factors are included, the adjusted R-squared in the MFM further rise to $36.3 \%$. The improvement in the adjusted R-squared by adding the spatial term drops to around 5\%. The spatial dependence coefficient drops to 0.519 for FDI and less than 0.5 for other weights. The results imply that the 
comovement is partially driven by spillovers from regional equity and real estate markets. However, the coefficient for spatial dependence is still significantly positive, confirming that the interconnectedness between countries can lead to co-movement more than what can be explained by global or regional factors.

\section{Table 4: Additional market indices for SMFM and MFM}

Note: The model is estimated from 1993M1 to 2015M3. The dependent variable is the log difference of the excess listed property index for each country in each month. SMFM in panel A has an additional factor comprising of the global listed property returns. The SMFM in panel B has an additional factor - the global direct real estate returns. The model in panel C consists of a number of regional factors. The spatial weight matrix is based on the bilateral FDI. $\rho$ is the coefficient for spatial dependence. Std $(\rho)$ is the standard deviation of $\rho . R 2$ is the average coefficient of determination. BIC stands for the Bayesian Information Criteria. $|\alpha|$ stands for the absolute mean of the individual alphas. Std $(\alpha)$ stands for the average standard deviation of alpha. The GRS is a test for the joint significance of the portfolio alphas. For example, for 14 portfolios and 324 monthly returns with 5 factors, the critical values for the GRS test for all models would be 1.55, 1.72 and 2.14 for the 10\%, 5\% and 1\% significance levels, respectively. With 14 portfolios and 324 monthly returns with 10 factors, the critical values for the GRS test for all models are 1.54, 1.72 and 2.14 for $10 \%, 5 \%$ and $1 \%$ significance level, respectively.

\begin{tabular}{|c|c|c|c|c|c|c|c|}
\hline & $\rho$ & $\operatorname{Std}(\rho)$ & $\mathrm{R} 2$ & $\mathrm{BIC}$ & $|\alpha|$ & $\operatorname{Std}(\alpha)$ & GRS \\
\hline \multicolumn{8}{|c|}{ Panel A: Global listed property returns } \\
\hline \multicolumn{8}{|l|}{ SMFM } \\
\hline Trade & $0.600^{* * *}$ & 0.014 & 0.385 & -3.107 & 0.003 & 0.002 & 1.418 \\
\hline Bank & $0.624^{* * *}$ & 0.012 & 0.375 & -3.096 & 0.003 & 0.002 & 1.524 \\
\hline $\begin{array}{l}\text { Portfolio } \\
\text { investment }\end{array}$ & $0.624^{* * *}$ & 0.013 & 0.382 & -3.102 & 0.003 & 0.002 & 1.385 \\
\hline FDI & $0.660^{* * *}$ & 0.014 & 0.385 & -3.114 & 0.003 & 0.002 & 1.420 \\
\hline MFM & & & 0.285 & -1.865 & 0.004 & 0.004 & $1.629^{*}$ \\
\hline
\end{tabular}

\section{SMFM}

$\begin{array}{llllllll}\text { Trade } & 0.670^{* * *} & 0.011 & 0.398 & -3.086 & 0.012 & 0.004 & 4.516^{* * *} \\ \begin{array}{l}\text { Bank } \\ \text { Portfolio }\end{array} & 0.690^{* * *} & 0.011 & 0.385 & -3.071 & 0.011 & 0.004 & 4.453^{* * *} \\ \text { investment } & 0.696^{* * *} & 0.012 & 0.396 & -3.089 & 0.012 & 0.004 & 4.585^{* * *} \\ \text { FDI } & 0.718^{* * *} & 0.010 & 0.399 & -3.097 & 0.011 & 0.004 & 4.697^{* * *} \\ \text { MFM } & & & 0.243 & -1.821 & 0.014 & 0.007 & 5.593^{* * *}\end{array}$

Panel C: Regional FF Factors + Regional listed property returns

\begin{tabular}{lllllllr} 
SMFM & & & & & & \\
Trade & $0.464^{* * *}$ & 0.015 & 0.416 & -3.244 & 0.004 & 0.002 & 1.474 \\
Bank & $0.473^{* * *}$ & 0.015 & 0.408 & -3.233 & 0.004 & 0.002 & $1.560^{*}$ \\
$\begin{array}{l}\text { Portfolio } \\
\text { investment }\end{array}$ & $0.485^{* * *}$ & 0.015 & 0.415 & -3.243 & 0.004 & 0.002 & $1.565^{*}$ \\
FDI & $0.519^{* * *}$ & 0.016 & 0.416 & -3.250 & 0.004 & 0.002 & 1.535 \\
MFM & & & 0.363 & -1.975 & 0.004 & 0.004 & $1.568^{*}$ \\
\hline
\end{tabular}


Further concerns include that only 14 countries are included in this study. The selection of countries is restricted by the availability of data, especially data on the linkages between markets. As a robustness check, we also include Singapore and Hong Kong, where REITs also have a long history. The results based on the 16 countries remain robust (Table 5). The spatial coefficient increases by $2 \%$ when Singapore and Hong Kong are added using geographic distance, maybe due to the more diversified geographic distribution of sample countries. The impact on economic linkages is limited, as the economic linkages are not completely determined by the geographic location of the country.

\section{Table 5: SMFM with alternative weight matrices for 16 countries}

Note: The model is estimated from 1993M1 to 2015M5. The dependent variable is the log difference of the excess listed property index for each country in each month. $\rho$ is the coefficient for spatial dependence. Std $(\rho)$ is the standard deviation of $\rho . R 2$ is the average coefficient of determination in the panel model. BIC stands for the Bayesian Information Criteria. $|\alpha|$ stands for the absolute mean of the individual alphas. $S t d(\alpha)$ stands for the average standard deviation of alpha. The GRS is a test for the joint significance of the portfolio alphas. With 16portfolios and 324 monthly returns, the critical values for the GRS test for all models are 1.49, 1.67 and 2.05 for 10\%, 5\% and 1\% significance level, respectively.

\begin{tabular}{lccccccc}
\hline & $\rho$ & $\operatorname{Std}(\rho)$ & $\mathrm{R} 2$ & $\mathrm{BIC}$ & $|\alpha|$ & $\operatorname{Std}(\alpha)$ & GRS \\
\hline SMFM & & & & & & & \\
Trade & $0.679^{* * *}$ & 0.011 & 0.382 & -2.988 & 0.003 & 0.002 & 1.170 \\
Portfolio investment & $0.696^{* * *}$ & 0.012 & 0.371 & -2.977 & 0.003 & 0.002 & 1.172 \\
Interest rate convergence & $0.651^{* * *}$ & 0.013 & 0.354 & -2.948 & 0.003 & 0.003 & 1.061 \\
Inflation convergence & $0.645^{* * *}$ & 0.013 & 0.348 & -2.936 & 0.003 & 0.003 & 1.080 \\
Cultural Similarity & $0.646^{* * *}$ & 0.014 & 0.348 & -2.926 & 0.003 & 0.003 & 1.116 \\
Openness Similarity & $0.640^{* * *}$ & 0.013 & 0.350 & -3.001 & 0.003 & 0.002 & 1.131 \\
Geographic distance & $0.658^{* * *}$ & 0.011 & 0.370 & -2.979 & 0.003 & 0.002 & 1.067 \\
MFM & & & 0.228 & -1.775 & 0.005 & 0.004 & 1.423 \\
\hline
\end{tabular}

\subsection{Rolling spatial coefficients}

Previous literature reported that there is unstable structure for REITs performance over the period from 1990 to 2015, especially during the crisis period. We first perform Chow tests with an unknown break point in the SMFM to test any significant changes in the coefficients. Figure 3 illustrates the F-statistics over time. The black line shows the critical value at the $1 \%$ and $5 \%$ significance level. We can see that the Chow statistic continuously exceeds the critical value during the period between 2004 and 2009, implying significant structural changes over this period.

Figure 3: Chow test with unknown break points 


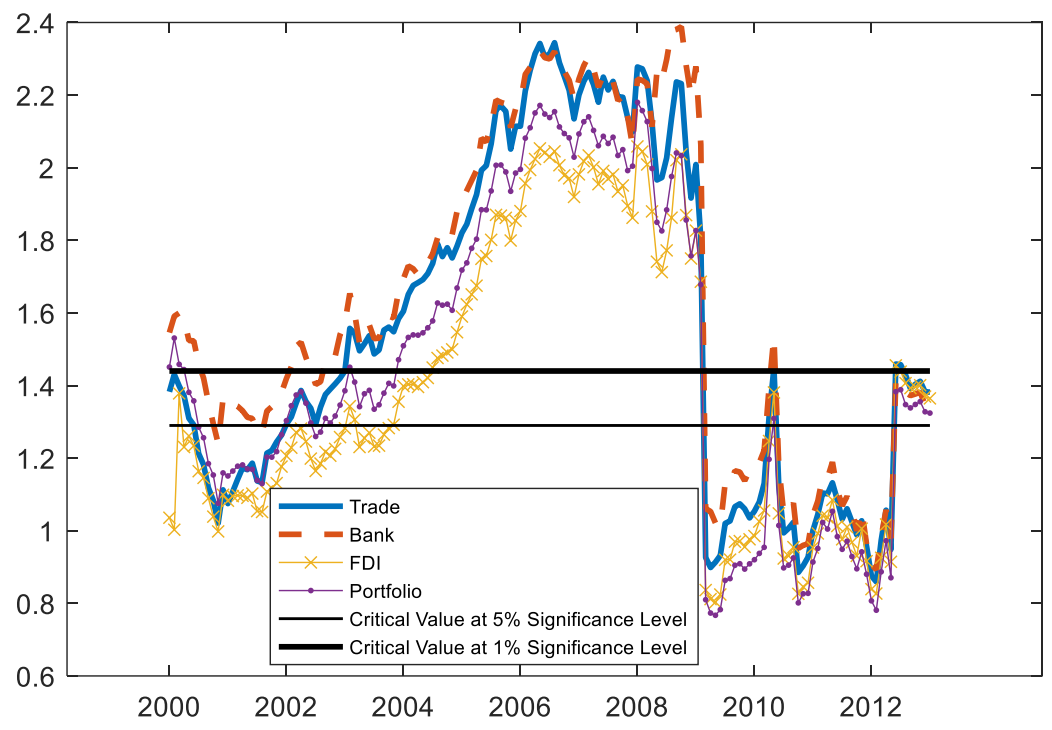

In order to illustrate how the interdependence across the markets changes over time, we estimate the SMFM using a rolling window of 36 months $^{8}$. The spatial coefficient $\rho$ is the same for each asset return but varies over time. The results for the different weight matrices are presented in Figure 4. The value of the spatial coefficient maters for the calculation of the asset variance capturing the spillover effects. We can see that the coefficient shows strong variation over time ranging from around 0.12 in 1997 to up to nearly 0.8 in 2008. It means that the co-movement between the index return rises sharply to $70-80 \%$ in 2007 and stays high during the crisis period. In a similar fashion, Lizieri (2013) estimates a three-factor model using a rolling window with equity, small cap and bonds to assess the returns of direct property in the UK. He shows that the parameters of the model are time-varying and the variation has increased during the global financial crisis and has not recovered by the end of 2011. Based on an international factor model, Milunovich and Trück (2013) find only a moderate increase in the correlation between individual REIT markets and regional/global REITs. Our study shows that, although the dependence of REIT excess returns on the regional/global REIT excess returns may not increase during the crisis period, the correlation between individual markets may still grow noticeably due to the rise in spatial dependence. Ignoring the spillover risk between markets may underestimate the correlation between assets, especially during the crisis period.

Another observation from Figure 3 while using a different weight matrix leads to more heterogeneous results in the late 1990s, the time-varying spatial coefficients converge across the different spillover channels over time and during the peak of the GFC. There would be almost no difference in the value of the coefficients. In 2012 we observe some divergence with FDI providing the upper bound and portfolio investment, the lower bound, of the value of the spatial coefficient.

\footnotetext{
${ }^{8}$ Using a different rolling window of either 24 months or 60 months, estimating here only a model with FDI weights for brevity, yields similar conclusions. Detailed results are available upon request from the authors.
} 
Figure 4: Estimated spatial coefficients based on a 36-month rolling window using alternative weight matrices

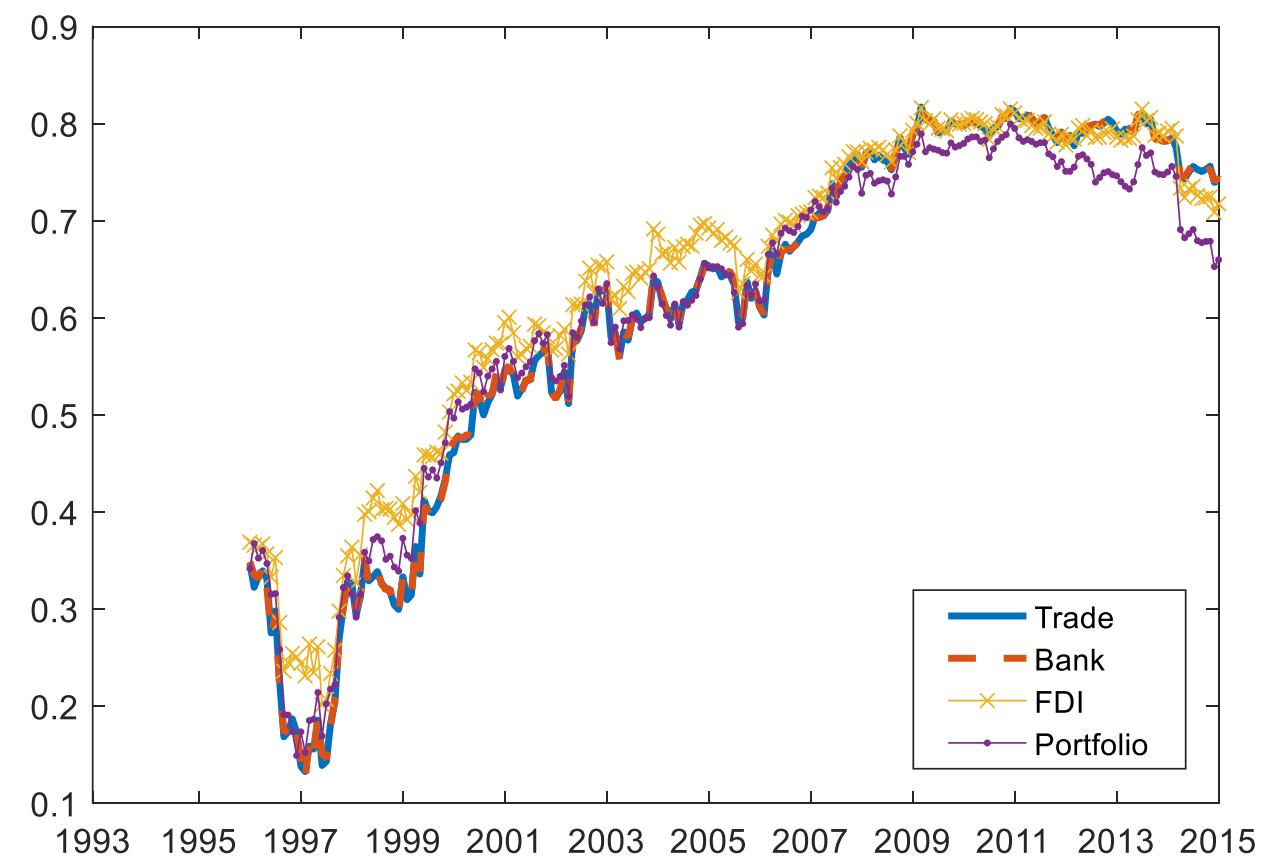

Adding further factors directly associated with the real estate market such as the IPD global direct property index or the EPRA/NAREIT global listed real estate stock index produces similar conclusions (see Figure 5). When regional factors and regional listed real estate stock indices are included, the spaital coefficient decreases noticablly. However, the spaital coefficeint still rises to $65 \%$ during the period between 2007 and 2009. This confirms a stronger comovement built upon the interconnectedness between countries in addition to spillovers from regional equity and real estate markets.

Figure 5: Estimated spatial coefficients using an FDI weight matrix and an additional real estate market factor based on a 36-month rolling window 


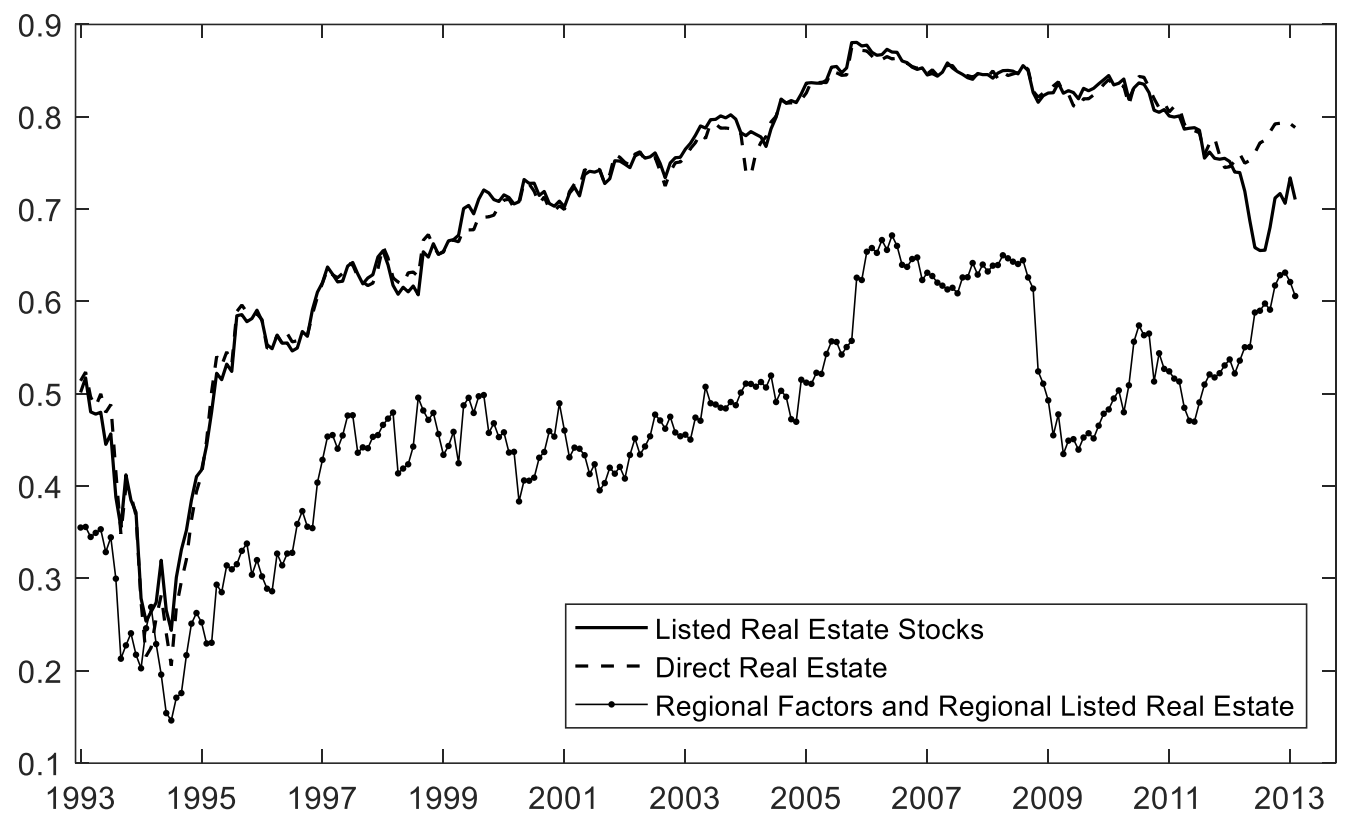

\subsection{Spillover risk}

Our main goal by estimating the SMFM is to disentangle the spillover risk from the total asset risk. We calculate the total asset risk, the idiosyncratic risk and the market risk using the asset return variance, the residual variance and the market factor variance, respectively. The total asset risk as estimated under the spatial factor model should be equivalent to the total asset risk as estimated under the factor model. However, a part of this risk, as modelled in the SMFM, will be attributed to spillovers across the asset returns which can potentially lead to contagion. The spillovers are larger for companies whose underlying assets are spatially 'closer' to each other in the broader sense as captured by the different weight matrices. An increase in those spillovers is associated with contagion.

Figure 6 shows the average results for the FDI weight matrix across all 14 markets. ${ }^{9}$ The graph on the left is based on the baseline model in which only global factors are included. The graph the right is based on the model with regional factors and real estate stock excess returns. Regional factors can explain a larger proportion of variations in REIT excess returns than global factors, implying that real estate equities may be priced regionally. We see that the conclusion regarding the spillover risk remain quite robust. Prior to the GFC, the idiosyncratic and the market risks remain at a relatively low level. With the onset of the crisis, we see a sharp jump in both risks with the market risk reaching its highest levels during the entire observation period. The idiosyncratic risk is also increasing substantially. This risk dynamics reflects the uncertainties associated with

\footnotetext{
${ }^{9}$ The results for the remaining matrices have similar outcomes.
} 
the underling local real estate market. Studies have shown that real estate stocks behave like stocks in the short term and like real estate in the long term. When the idiosyncratic risk falls at such low levels, as has happened in the first half of the last decade, before it rises again in the onset of the GFC, real estate stocks may reflect the dynamics on the equity market. It may be associated with increased transparency and liquidity on the real estate market. Milunovich and Trück (2013) also show significant increase in the correlation between REIT indices and regional/global equity indices. Starting in 2008 the idiosyncratic risk has increased again along with the market risk suggesting that during distressed periods the dynamics in the real estate stock returns is not only driven by general economic conditions but also by asset-specific risks which we argue are transmitted to other stocks leading to contagion. We can see that the spillover risk (the red line) in Figure 6 makes up for up to $60 \%$ of the total asset risk. Up until 2007, spillovers were hardly observed across the assets. With the onset of the GFC spillovers have increased dramatically. The increase in the spillover risk is seen as evidence of contagion. As a result, a global asset portfolio may not provide the necessary diversification benefits during a crisis period because, first, the sensitivity to market fluctuations increases and, second spillover risks.

\section{Figure 6: Variance decomposition based on a SMFM with FDI weights - average across countries}

(1) Using global factors

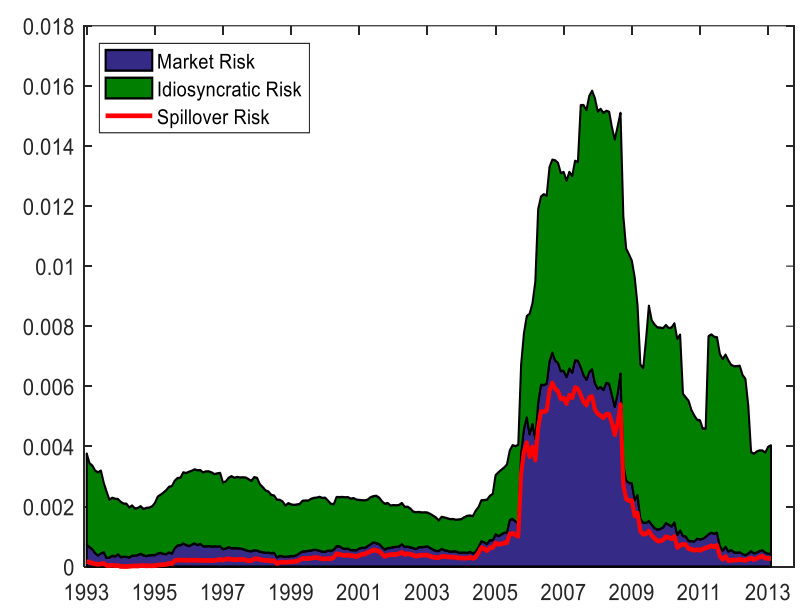

(2) Using regional factors and real estate factor

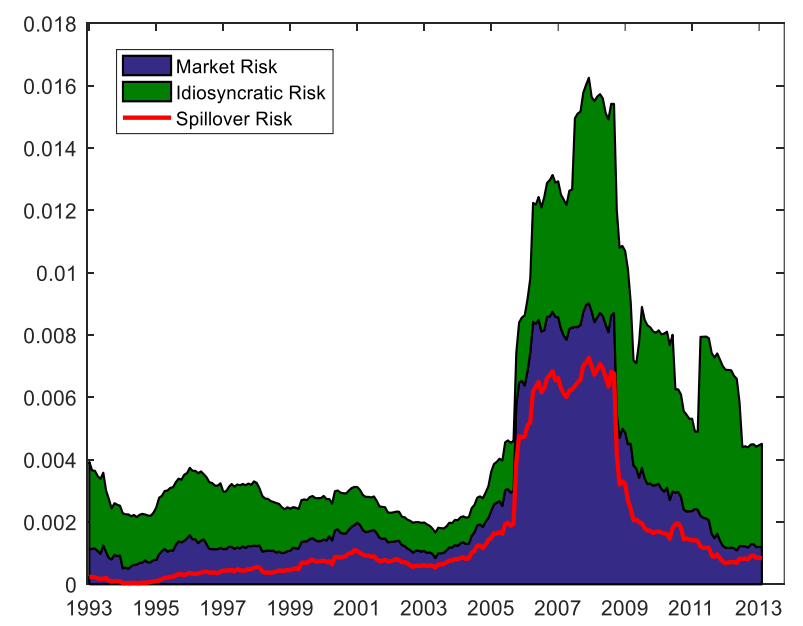

Figure 7 illustrates the spillover, systematic and idiosyncratic risks for US, UK and Japanese REITs. For the US and UK, we can see remarkable increase in the systematic risk and idiosyncratic risk during the GFC, while for Japanese REITs, the overall risk is not different from what it used to be in the early 2000s. US and UK REITs are more seriously affected by the global crisis than Japanese REITs. Spillover risk rises in all three countries during the GFC period, indicating that the contagion between REITs markets is built upon the economic linkages. In the US, the spillover risk explains the largest proportion of variations in the REITs returns, with a maximum of $85 \%$ 
during the GFC period. This may be due to the strong FDI exposure between the US and other countries. In the UK, the spillover risk is smaller than in the US, but it still accounts for $77 \%$ of the total variance during the crisis period. The Japanese REIT market also exhibits noticeable spillover risks during the GFC, which is up to $65 \%$ of the total variance.

Figure 7: Variance decomposition based on a SMFM with FDI weights - US, UK and Japan

US

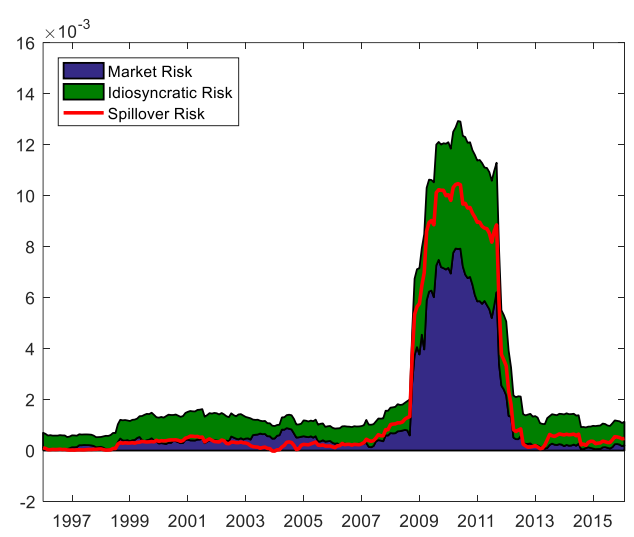

Japan

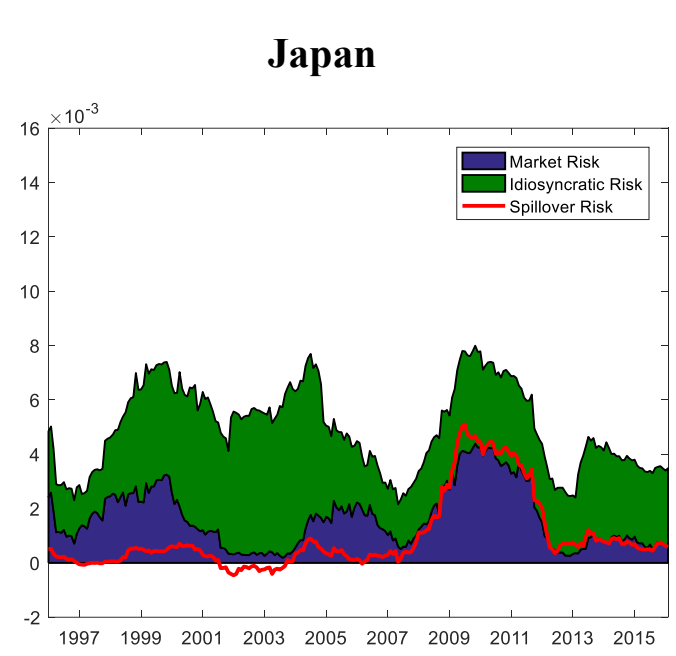

UK

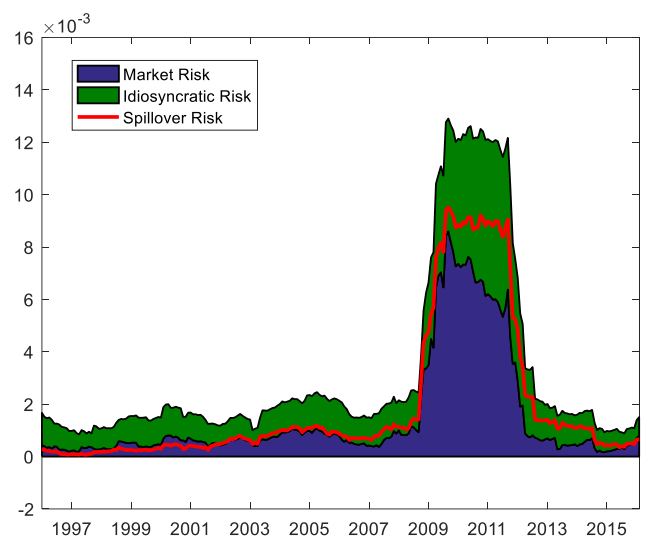

\section{Conclusion}

This paper estimated a global spatial multi-factor model by incorporating various spatial linkages across REIT index returns. Our measures of spatial proximity include bilateral trade flows, geographic distance, cultural proximity and financial integration. We account for an increase in the interdependence between the REIT index returns during normal and distressed periods by estimating time-varying coefficients. We use the spatial linkages to disentangle spillover risks in addition to market and idiosyncratic risks by decomposing the asset variance into a spatial and non-spatial part. Our results show that during the GFC, the spatial interdependence between REIT 
indices remarkably increases, and triggers strong contagion effects through the spillover channels. The spillover risk can explain up to $60 \%$ of total asset risk during the GFC. Our results have implications for investors showing that the market can channel asset volatility leading to contagion during crisis periods and therefore linkages between country indices need to be accounted for as a means of assessing the diversification benefits of a global portfolio. 


\section{References}

Akinsomi, O., S. E. Ong, M. F. Ibrahim and G. Newell. 2013. The idiosyncratic risks of a Shariah compliant REIT investor. Journal of Property Research 31(3), 211-243.

Anselin, L. 2006. Spatial econometrics. In: Mills, T.C., Patterson, K. (Eds.), Palgrave Handbook of Econometrics, Econometric Theory, vol. 1. Basingstoke, Palgrave Macmillan, 901-969.

Anton, M. and C. Polk. 2014. Connected stocks. Journal of Finance, 69(3), 1099 - 1127.

Asgharian, H., W. Hess and L. Liu. 2013. A spatial analysis of international stock market linkages. Journal of Banking and Finance 37, 4738-4754.

Beine, M., A. Cosma and R. Vermeulen. 2010. The dark side of global integration: Increasing tail dependence. Journal of Banking and Finance 34, 184-192.

Bekaert, G. M. Ehrmann, M. Fratzscher and A. Mehl. 2014. The global crisis and equity market contagion. Journal of Finance 69(6), 2597-2649.

Blundell, G., S. Fairchild and R. Goodchild. 2005. Managing portfolio risk in real estate. Journal of Property Research 22(2-3), 115-136.

Bond, S.A., Dungey, M. and Fry, R. 2006, A web of shocks: crises across Asian real estate markets, Journal of Real Estate Financial Economics, Vol. 32, pp. 253-74.

Bruno, V. and H. S. Shin. 2014. Cross-border banking and global liquidity. Princeton University Working Paper.

Chang D.G., C. Chen 2014. Evidence of Contagion in Global REITs Investment. International Review of Economics and Finance. 31. 148-158

Chiang, K. 2009. REIT idiosyncratic risk. Journal of Property Research 26(4), 349 - 366.

Claessens, S. and K. Forbes. 2001. International Financial Contagion. Springer: New York.

Conley, T. G. and G. Topa. 2002. Socio-economic distance and spatial patterns in unemployment. Journal of Applied Econometrics 17, 303-327.

Cooper, I. and E. Kaplanis. 1994. Home bias in equity portfolios, inflation hedging, and international capital market equilibrium. Review of Financial Studies 7, 45-60.

Crosby, N., C. Jackson and A. Orr. 2016. Refining the real estate pricing model. Journal of Property Research 33(4), 332-358.

De Bandt,O. and P. Hartmann. 2000. Systemic risk: A survey. European Central Bank Working 


\section{Paper 35.}

Eder, A. and Keiler, S. 2015. CDS Spreads and Contagion among Systemically Important Financial Institutions - A Spatial Econometric Approach International Journal of Finance \& Economics.

Eickmeier, S. and T. Ng. 2011. How do credit supply shocks propagate internationally? A GVAR approach. CEPR Discussion Paper 8720.

Fama, E. and K. French. 2012. Size, value, and momentum in international stock returns. Journal of Financial Economics, 105, 457-472.

Fernandez, V. Spatial Linkages in International Financial Markets. Quantitative Finance, 11 (2) (2011), 237-245.

Forbes, K. and R. Rigobon. 2002. No contagion, only interdependence: Measuring stock market comovements, Journal of Finance 57, 2223-2261.

Forni, M. and Lippi, M. 2001. The generalized dynamic factor model: Representation theory. Econometric Theory, 17, 1113-1141.

Fry, R., Martin, V. and Tang, C. 2010, A new class of tests of contagion with applications, Journal of Business and Economic Statistics, Vol. 28 No. 3, pp. 423-37.

Gerlach, R., Wilson, P. and Zurbruegg, R. 2006. Structural breaks and diversification: the impact of the 1997 Asian financial crisis on the integration of Asia-Pacific real estate markets, Journal of International Money and Finance, Vol. 25, pp. 974-91.

Gibbons, M.R., Ross, S.A. and Shanken, J., 1989. A test of the efficiency of a given portfolio. Econometrica 57, 1121-1152.

Haining, R. 2003. Spatial Data Analysis: Theory and Practice, Cambridge University Press: Cambridge.

Hartmann, P., S. Straetmans and C. G. de Vries. 2004. Asset market linkages in crisis periods. Review of Economics and Statistics 86(1), 313-326.

Hoesli, M. and Reka, K. 2012. Volatility spillovers, comovements and contagion in securitized real estate markets, Journal of Real Estate Finance and Economics. Volume 47, Issue 1, pp 1-35

Holly, S., M. H. Pesaran and T. Yamagata. 2011. The spatial and temporal diffusion of house prices in the UK. Journal of Urban Economics 69, 2-23.

Kou, S. X. Peng and H. Zhong. (2017). Asset Pricing with Spatial Interaction. Management Science. Forthcoming. 
LeSage, J. and R. K. Pace. 2009. Introduction to spatial econometrics. Chapman \& Hall/ CRC, Boca Raton.

Liow. K. H. 2007. The dynamics of return volatility and systematic risk in international real estate security markets. Journal of Property Research 24(1), 1-29.

Lizieri, C. 2013. After the fall: Real estate in the mixed-asset portfolio in the aftermath of the global financial crisis. The Journal of Portfolio Management 39(5), 43-59.

MacGregor, B. and G. Schwann. 2011. Common features in UK commercial real estate returns. Journal of Property Research 20(1), 23-48.

Marston, R. C. 1997. International financial integration: A study of interest differentials between the major industrial countries. Cambridge University Press.

Milcheva, S. and B. Zhu. 2015. Bank integration and co-movements across housing markets. Journal of Banking and Finance. doi:10.1016/j.jbankfin.2015.07.002.

Milcheva, S. and B. Zhu. 2018. Spatial dependence in asset pricing models. Working Paper. Reading University.

Milunovich, G. and S. Trück. 2013. Regional and global contagion in real estate investment trusts: The case of the financial crisis of 2007-2009. Journal of Property Investment \& Finance, Vol. 31 Issue: 1, pp.53-77.

Pesaran, M. H. and Tosetti, E. 2011. Large panels with common factors and spatial correlation. Journal of Econometrics, 161, 182-202.

Portes, R. and H. Rey. 2005. The determinants of cross-border equity flows. Journal of International Economics 65, 269-296.

Shin, H. S. 2012. Global banking glut and loan risk premium. IMF Economic Review 60(2), 155192.

Wälti, S. 2010. Stock market synchronization and monetary integration. Journal of International Money and Finance 30, 96-110.

Zhu, B., R. Fuess and N. Rottke. 2013. Spatial linkages in returns and volatilities among US regional housing markets. Real Estate Economics 41 (1), $29-64$. 


\section{Appendix}

This Appendix show the formula used to construct the weights in Section 3.3. The weight matrix is constructed in two steps. First, we calculate the distance or proximity between each two markets. Then we transform the measure of proximity to a weight which is standardized. We consider a variety of the linkages between countries:

\section{Foreign direct investment}

We calculate the importance of country $j$ for country $i$ by taking the FDI between the two countries as a proportion of the total FDI of country $i$ with all other countries:

$$
F_{i, j, t}^{F D I}=\frac{\text { Outward }_{i, j, t}+\text { Outward }_{i, j, t}}{\sum_{k} \text { Outward }_{i, k, t}+\sum_{k} \text { Outward }_{k, i, t}}
$$

where Outward ${ }_{i, j, t}$ stands for the outward foreign direct investment from country $i$ to country $j$, and $k=1, \ldots, N$.

The FDI linkage can also be defined based on the outward and inward FDI separately, e.g. $F_{i, j, t}^{\text {Out }}=\frac{\text { Outward }_{i, j, t}}{\sum_{k} \text { Outward }_{i, j, t}}$, and $F_{i, j, t}^{\text {In }}=\frac{\text { Inward }_{i, j, t}}{\sum_{k} \text { Inward }_{i, j, t}}$, but both weights generate very similar results, and also similar results with the weight based on total inward and outward FDI. The reason may be in the small difference between the outward FDI flow and the inward FDI flow. Therefore, we only report the results based on total FDI.

\section{Portfolio investment linkages}

We calculate the importance of country $j$ for country $i$ by taking the portfolio investment between the two countries as a proportion of the total portfolio investment of country $i$ with all other countries:

$$
F_{i, j, t}^{P F I}=\frac{\text { Outward }_{i, j, t}+\text { Outward }_{j, i, t}}{\sum_{k} \text { Outward }_{i, k, t}+\sum_{k} \text { Outward }_{k, i, t}} .
$$

\section{Trade linkages}

We calculate the importance of country $j$ for country $i$ by taking the trade between the two countries as a proportion of the total trade of country $i$ with all other countries:

$$
F_{i, j, t}^{\text {Trade }}=\frac{\text { Export }_{i, j, t}+\text { Export }_{j, i, t}}{\sum_{k} \text { Export }_{i, k, t}+\sum_{k} \text { Export }_{k, i, t}} .
$$

\section{Bank foreign exposure}


We calculate the ratio of the bank claims between each two countries to the sum of total bank claims of each of the two countries:

$$
F_{i, j, t}^{\text {bank }}=\frac{\operatorname{Claim}_{i, j, t}+\operatorname{Claim}_{j, i, t}}{\sum_{k} \operatorname{Claim}_{i, k, t}+\sum_{k} \operatorname{Claim}_{k, i, t}}
$$

where Claim $_{i, j, t}$ stands for the bank claim from country $i$ to country $j . F_{i, j, t}^{b a n k}$ measures the importance of country $j$ for country $i$ in terms of bank integration and $k=1, \ldots, N$.

\section{Cultural similarity}

We estimate cultural similarity hence as follows:

$F_{i, j}^{\text {Culture }}=\mid$ Culture $_{i}-$ Culture $_{j} \mid$.

where Culture $_{i}$ is the average value of the six Hofstede scores for country $i$.

\section{Openness Similarity}

We calculate the openness proximity between two countries $i$ and $j$ as:

$F_{i, j, t}^{o p e n}=\mid$ Open $_{i, t}-$ Open $_{j, t} \mid$

where open $_{i, t}$ is the openness score in country $i$ at period $t$.

\section{Interest rate convergence}

We use the difference in the 3-month money market rate $(I R)$ between country $i$ and country $j$ and also account for fluctuations in exchanges rate by subtracting the purchasing power parity (PPP) between the two countries:

$$
F_{i, j, t}^{I R}=\left|I R_{i, t}-I R_{j, t}-E_{t-1}\left(\frac{F X_{i j, t}}{F X_{i j, t-1}}-1\right)\right|,
$$

where $F X_{i, j}$ is the expected growth of the price of one unit of currency in country $j$ in terms of the currency in country $i$ and $I R$ is the interest rate.

\section{Inflation convergence}

The inflation proximity between two countries is calculated as: 


$$
F_{i, j, t}^{c p i}=\left|I N F L_{i, t}-I N F L_{j, t}-E_{t-1}\left(\frac{F X_{i j, t}}{F X_{i j, t-1}}-1\right)\right|,
$$

where $F X_{i, j}$ is the expected growth of the price of one unit of currency in country $j$ in terms of the currency in country $i$ and INFL is the inflation rate.

\section{Geographic distance}

We measure geographic proximity $\left(F_{i, j}^{D}\right)$ based on the distance $\left(D_{i, j}\right)$ between the capital cities of each pair of countries $i$ and $j$ :

$F_{i, j}^{D}=D_{i, j}$

In the second step, we convert the $F$ matrix to a corresponding continuity matrix $C$ whose elements $c_{i, j, t}$ are defined as:

$c_{i, j, t}=1-\frac{\max _{j, t} F_{i, j, t}-F_{i, j, t}}{\max _{j, t} F_{i, j, t}-\min _{j, t} F_{i, j, t}}$,

when $F_{i, j, t}$ is a measure of linkage / similarity, or

$c_{i, j, t}=1-\frac{F_{i, j, t}-\min _{j, t} F_{i, j, t}}{\max _{j, t} F_{i, j, t}-\min _{j, t} F_{i, j, t}}$,

when $F_{i, j, t}$ is a measure of distance / dissimilarity.

The weight matrix $W$ is then obtained from $C$ through row standardisation, such that for each $i$, $\sum_{j, t} w_{i, j, t}=1$. If the weight matrix is constructed skipping this second step, it will remain symmetric. The second step assures that the matrix is not necessarily symmetric, so that even if country $i$ is an important neighbour for country $j$ (i.e., $\mathrm{c}_{j, i, t}$ is close to one), country $j$ may be not important for country $i$ (i.e., $\mathrm{c}_{i, j, t}$ is close to zero). 